\title{
VLF Signal Anomalies During Cyclone Activity in the Atlantic Ocean
}

\author{
NaitAmor, S.; Cohen, M. B.; Kumar, Sushil; Chanrion, O.; Neubert, T.
}

\section{Published in:}

Geophysical Research Letters

Link to article, DOI:

10.1029/2018GL078988

Publication date:

2018

Document Version

Publisher's PDF, also known as Version of record

Link back to DTU Orbit

Citation (APA):

NaitAmor, S., Cohen, M. B., Kumar, S., Chanrion, O., \& Neubert, T. (2018). VLF Signal Anomalies During Cyclone Activity in the Atlantic Ocean. Geophysical Research Letters, 45(19), 10,185-10,192.

https://doi.org/10.1029/2018GL078988

\section{General rights}

Copyright and moral rights for the publications made accessible in the public portal are retained by the authors and/or other copyright owners and it is a condition of accessing publications that users recognise and abide by the legal requirements associated with these rights.

- Users may download and print one copy of any publication from the public portal for the purpose of private study or research.

- You may not further distribute the material or use it for any profit-making activity or commercial gain

- You may freely distribute the URL identifying the publication in the public portal 


\section{Geophysical Research Letters}

\section{RESEARCH LETTER \\ 10.1029/2018GL078988 \\ VLF Signal Anomalies During Cyclone Activity in the Atlantic Ocean}

\begin{abstract}
Key Points:
- Very low frequency (VLF) signal perturbations were observed due to hurricanes and tropical storms in the Atlantic Ocean

- The signal perturbations at nighttime were of durations between 2 to $3 \mathrm{hr}$

- The sensitivity zone of VLF propagation to the center of hurricanes and tropical storms can extend up to a distance of $2,000 \mathrm{~km}$
\end{abstract}

Correspondence to:

S. NaitAmor,

snaitamor@yahoo.com

Citation:

NaitAmor, S., Cohen, M. B.,

Kumar, S., Chanrion, O., \& Neubert, T. (2018). VLF signal anomalies during cyclone activity in the Atlantic Ocean. Geophysical Research Letters, 45, 10,185-10,192. https://doi.org/10.1029/2018GL078988

Received 3 JUN 2018 Accepted 17 SEP 2018 Accepted article online 21 SEP 2018 Published online 11 OCT 2018

(O2018. American Geophysical Union. All Rights Reserved.

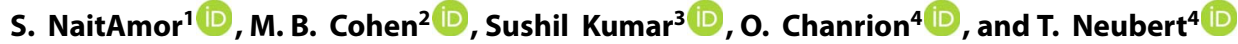 \\ ${ }^{1}$ Astrophysics Division, CRAAG, Algiers, Algeria, ${ }^{2}$ School of Electrical and Computer Engineering, Georgia Institute of \\ Technology, Atlanta, GA, USA, ${ }^{3}$ School of Engineering and Physics, University of the South Pacific, Suva, Fiji, ${ }^{4}$ Technical \\ University of Denmark, Kongens Lyngby, Denmark
}

Abstract In this paper we present ionospheric disturbances during the simultaneous presence of two to three Large Meteorological Systems, classified as hurricanes and tropical storms, in the Atlantic Ocean from August to November 2016. The ionospheric disturbances were detected by very low frequency $(3-30 \mathrm{kHz})$ signals from two North American transmitters observed in Algiers $\left(36.75^{\circ} \mathrm{N}, 03.47^{\circ} \mathrm{E}\right)$. The results show clear anomalies in the amplitude both at nighttime and at daytime. At nighttime, the anomalies were observed in association with all Large Meteorological Systems even at low stage of storm intensity (tropical depression). The anomalies showed periodicities between 2 and $3 \mathrm{hr}$ with a strong decrease in the signal amplitude. The wave-like features were confirmed by the mother wavelet analysis of the normalized signal amplitude. These signal anomalies may result from traveling ionospheric disturbances generated by tropical storms and hurricanes associated gravity waves.

Plain Language Summary Hurricanes and tropical storms are severe atmospheric weather phenomena that can affect drastically the human life. The effect of this kind of events is not only limited to ground level but also extends through the atmosphere to the high altitudes. One of the most important features of these events, which has an impact on the atmospheric dynamic and possibly climate variability, is the gravity waves (GWs). GWs propagate upward and outward and have been detected up to the top of the ionosphere. This work gives a clear evidence of the GWs effect on the lower region of the ionosphere (50-90 km) and in the middle atmosphere (mesosphere), that have been comparatively less studied. With very low frequency signal analysis we found that the GWs are able to modify the propagation of the radio signals even if the perpendicular distance of the storm center to the signal path is larger than 1,000 km. Additionally, the wavelet analysis of the very low frequency signal amplitude for several days showed a wave-like activity between periods of 2 to $3 \mathrm{hr}$, which are typical to GWs.

\section{Introduction}

Very low frequency $(\mathrm{VLF}, 3-30 \mathrm{kHz}$ ) radio remote sensing has long been used to study the $D$ region $(60-90 \mathrm{~km})$ of the ionosphere. VLF radio waves propagate with low loss (attenuation rates of a few $\mathrm{dB} / \mathrm{Mm}$ ) to global distances by multiple reflections between the ground and the lower part of the ionosphere. Monitoring the amplitude and phase of a VLF beacon at a receiver that may be thousands of km away from transmitter gives insights into the ionospheric conditions, mainly electron density and collision frequency, anywhere along the Great Circle Path (GCP) between the transmitter and the receiver. This fact has been used to study solar flares (Raulin et al., 2013; Thomson et al., 2005), solar terminator (Nina \& Cadez, 2013), geomagnetic storms (Kumar et al., 2015), thunderstorm and early events (Haldoupis et al., 2010; NaitAmor et al., 2013; Salut et al., 2012), solar eclipses (Cohen, Said, et al., 2018), and other phenomena. In addition to these well-known disturbances, some research works on the effect of cyclone and tropical storm (TS) on the $D$ region and the lower atmosphere using the VLF technique have been done. For example, Marshall and Snively (2014) found one case of thunderstorm-driven acoustic waves generating oscillations in the VLF signal amplitude with a period of few minutes. Rozhnoi et al. (2014) showed that anomalies in the signal amplitude can occur when cyclones are closer to the transmitter-receiver GCP. Kumar et al. (2017) used data of four different VLF transmitters (NPM, NLM, NAA, and IJ) recorded in Fiji to study the effect of cyclone Evan (category 4) on the propagation of the VLF signals. In addition to the observation of anomalies in the signals, they used the Long Wave Propagating Capability code (Ferguson, 1992; Ferguson \& Snyder, 1989a) to find the TC-associated changes in the 

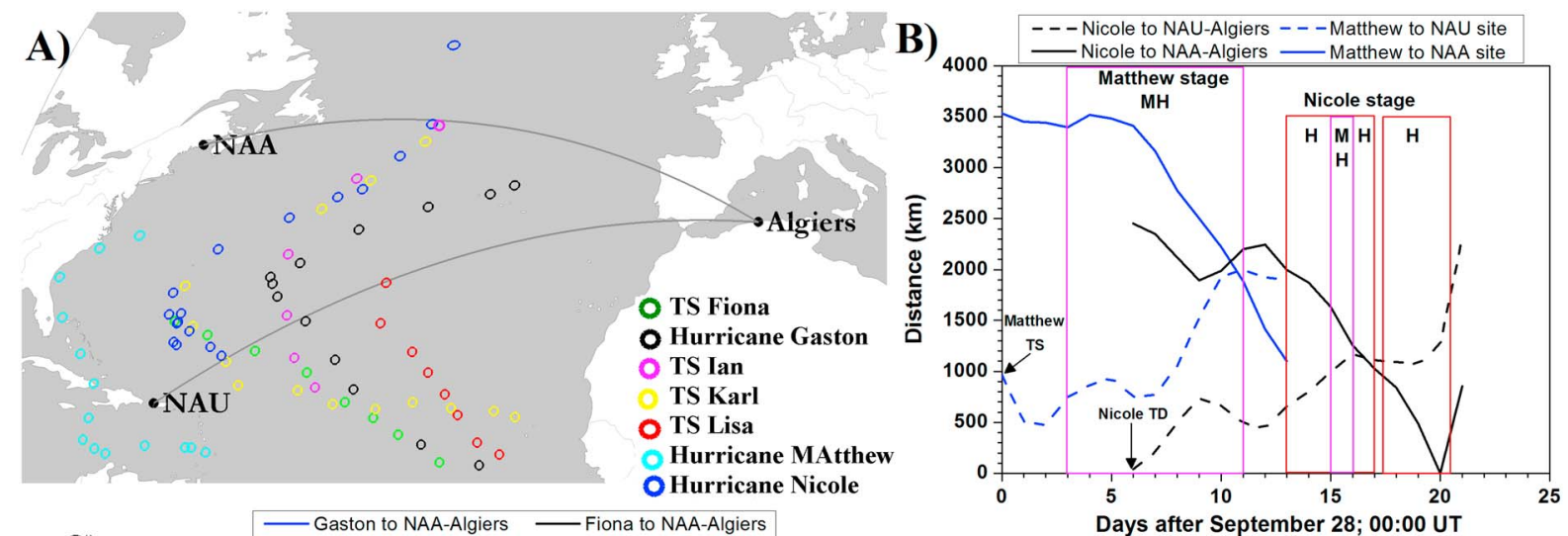

C)

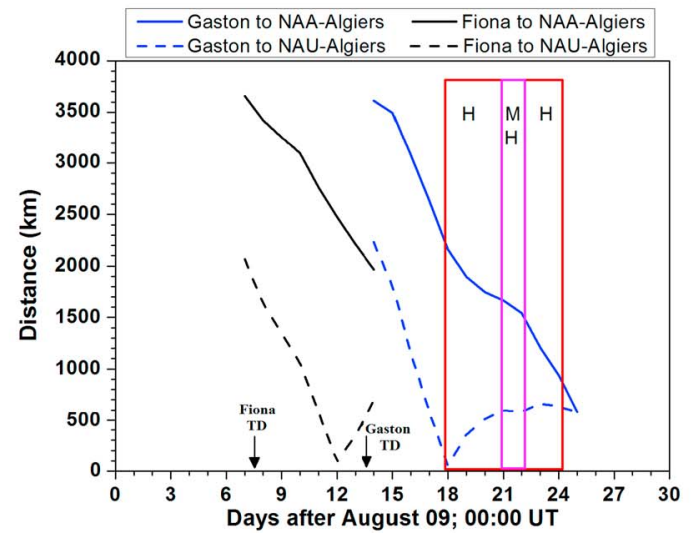

D)

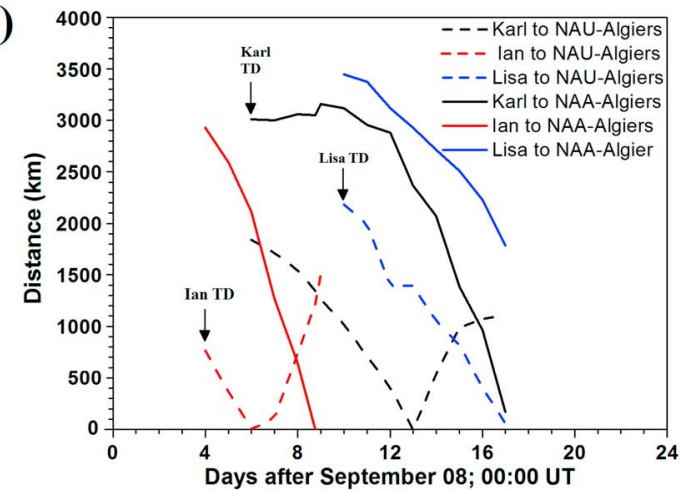

Figure 1. (a) Transmitters-receiver Great Circle Paths and the studied convective system track paths. (b) Distances from storm. Matthew to NAA and NAU sites and Nicole distances to GCPs. (c) Storms Fiona and Gaston distances to GCPs. (d) Storms lan, Karl, and Lisa distances to GCPs.

$D$ region reference height, electron density, and electron density gradients. They accounted the changes in these parameters to the gravity waves (GWs) associated with TC Evan. More information on the GW formation, sources, observations, and simulation can be found in the papers (Brissaud et al., 2016; Garcia \& Solomon, 1985; Liu et al., 2014; Sato et al., 2009). In this work we present VLF signal anomalies associated with hurricanes and TSs in the Atlantic Ocean. Since two to three storms developed during the same period, we then have divided them to three cases according to the period of observation. We describe the instrumentation and data analysis method and show some examples of signal perturbations due to the most important TSs and hurricanes. Then, we utilize the mother wavelet analysis to determine the features of traveling ionospheric disturbances observed during the storms.

\section{Data Analysis}

The hurricanes and TSs considered in this analysis occurred between August and November 2016 in the Atlantic Ocean. They were classified as TS or hurricane of categories 1-5 by the National Hurricane Center (www.nhc.noaa.gov) based on the sustained wind speed. We considered seven storms: Fiona (TS), Gaston (category 3 hurricane), lan (TS), Karl (TS), Lisa (TS), Matthew (category- 5 hurricane) and Nicole (category- 4 hurricane). Figure 1a shows the locations of the VLF receiver in Algiers $\left(36.75^{\circ} \mathrm{N}, 03.47^{\circ} \mathrm{E}\right.$ ) (Algeria) along with two U.S. Navy VLF transmitters known as NAA in Maine $\left(44.64^{\circ} \mathrm{N}, 67.28^{\circ} \mathrm{W}, 24 \mathrm{kHz}\right)$ and NAU in Puerto Rico $\left(18.4^{\circ} \mathrm{N}\right.$, $67.17^{\circ} \mathrm{W}, 40.7 \mathrm{kHz}$ ). The GCPs from the transmitters to the receiver are shown, and the circles show the track paths of the storms. In Figures $1 \mathrm{~b}-1 \mathrm{~d}$, we plotted the distances from the storms' center to each GCP on different days. The black arrows refer to periods when the storms were classified as TD. The extremely low frequency ELF/VLF receiver known as Atmospheric Weather Electromagnetic System for Observation Modeling and Education (AWESOME) has been described in detail by Cohen et al. (2010). A more recent version is described by Cohen, Gross, et al. (2018) and the installation has been described by NaitAmor et al. (2010). Here we used low-time resolution (1 s) of NAA and NAU transmitters signal amplitudes as measured in Algiers. The phase of the signal is also available but is not used here because of large gap from day to day. Some of the selected storms crossed GCPs while others moved between NAU-Algiers and NAA-Algiers GCPs. The analysis technique 
is as follows: We first identified the storms' starting and ending days, and then based on this, we separated them into three time periods. The first period is from 16 August to 3 September, which includes development of Gaston and Fiona. The second time period is from 12 to 25 September, which includes development of Karl, Ian, and Lisa. The third time period is from 28 September to 29 October, which includes development of Nicole and Matthew. For each time period, we selected days at least 1 week before the starting day of the first classified storm and 1 week after the ending day of the last classified storm and took these as references or controls. Using the amplitude variation on the control days we calculated the diurnal mean signal amplitude $\left(A_{\text {normal }}\right)$ at every second as well as the standard deviation $(\sigma)$ to establish a range of typical diurnal amplitude in the absence of any major storm. Prior to doing this, we manually removed any lightning fingerprints known as sferics and solar flare-associated VLF perturbations. We also removed duration of data when any transmitter was off. We then compared the variation of VLF transmitter signal amplitude on the storm days with mean amplitude on reference (or control) days. We define a perturbation as when the amplitude exceeds the range defined by $3 \sigma$ from the mean, which is the same as defined by (Kumar et al., 2017). Morlet wavelet analysis is applied to the normalized amplitudes of the signals to identify any signature of GWs associated with TSs and hurricanes.

\section{Observations}

\subsection{Fiona and Gaston Cases}

Hurricane Gaston started as tropical depression on 22 August and dissipated around 3 September 2016. It was classified as hurricane $(\mathrm{H})$ and major hurricane $(\mathrm{MH})$ for many days when it moved between NAU and NAA paths to Algiers. TS Fiona developed between 16 and 23 August. During this period the geomagnetic conditions were normal with Kp index ranging between 0 and 3 except for some days when Kp was between 4 and 6. These conditions were due to a geomagnetic storm on 24 August and 1 September where minimum Dst values were -70 and $-60 \mathrm{nT}$ according to Coordinated Data Analysis Web.

In Figure 2a we present the NAU signal amplitude for 3 days starting from 21 August (day 12) to 24 August and covering a period when Fiona approached the NAU-Algiers GCP and then crossed it. For NAA transmitter we show the signal amplitude for three days starting from 1 September (day 23) during which Gaston was hurricane and then recovered to TS around midday of 2 September, see Figure $2 \mathrm{~b}$. The daily variation of the undisturbed signal on control days shows high amplitude during the nighttime followed by a period of large decrease and increase in the amplitude and finally a stable signal amplitude in the daytime. The decrease and increase in the signal amplitude is due to the day/night terminator transition effect (Nina \& Cadez, 2013). The periods of amplitude excursion beyond $\mp 3 \sigma$ are marked with blue arrows, and the green arrows refer to the periods when data were not recorded. The periods when Gaston was classified as hurricane and major hurricane are marked by red and pink rectangles in the Figure 1c, respectively. This color code is also used in the other figures. From the plots, important anomalies in the signal amplitude were observed which are likely due to the two convective systems. Effectively, taking the normal signal amplitude as a reference, a strong perturbation (decrease) of $-8 \mathrm{~dB}$ in the nighttime amplitude of NAA signal on 1 September was recorded when Gaston was hurricane of category 3. For NAU signal, we observed a strong decrease of $-12 \mathrm{~dB}$ in the signal amplitude associated with TS Fiona when it approached and then crossed NAU-Algiers path. To show more clearly the signal perturbations due to the storms, we plot in Figure $2 c$ and $2 d$ the daily variation of the normalized amplitude from 9 August to 8 September of both VLF signals. Here the normalized signal amplitude is given by $A_{\text {normalized }}=\left(A_{\text {perturbed }}-A_{\text {normal }}\right) / \sigma$. As can be seen from Figures $2 \mathrm{c}$ and $2 \mathrm{~d}$, before the onset of each storm the signal amplitude variation was between $\mp 3 \sigma$. After that, strong perturbations in the amplitudes were recorded during the approaching time of the storms toward the GCPs. We also observed a signal perturbation for the NAU-Algiers path at the nighttime on 16 August (day 7) when storm Fiona was in its TD classification. Another interesting finding is the nighttime wave-like events with periods between 2 and $3 \mathrm{hr}$ observed in both signal amplitudes (NAU and NAA) with different shapes and magnitudes below $3 \sigma$. These wave-like features are confirmed by the mother wavelet analysis of normalized NAU signal amplitude and NAA signal amplitude shown in Figures $2 \mathrm{e}$ and $2 \mathrm{f}$, respectively.

\subsection{Ian, Karl, and Lisa Cases}

The second interesting convective systems are the storms: lan (developed from 12 to 16 September), Karl (developed from 14 to 25 September), and Lisa (developed between 19 and 24 September). The geomagnetic index $\mathrm{Kp}$ from 8 September to 2 October varied between 0 and 3 except for few days where Kp increased to 6. This was also due to a moderate geomagnetic storm with a minimum Dst index of $-70 \mathrm{nT}$. In Figures $3 a$ and $3 b$ we present the signal amplitudes of NAA and NAU transmitters for 3 days starting from 22 September 

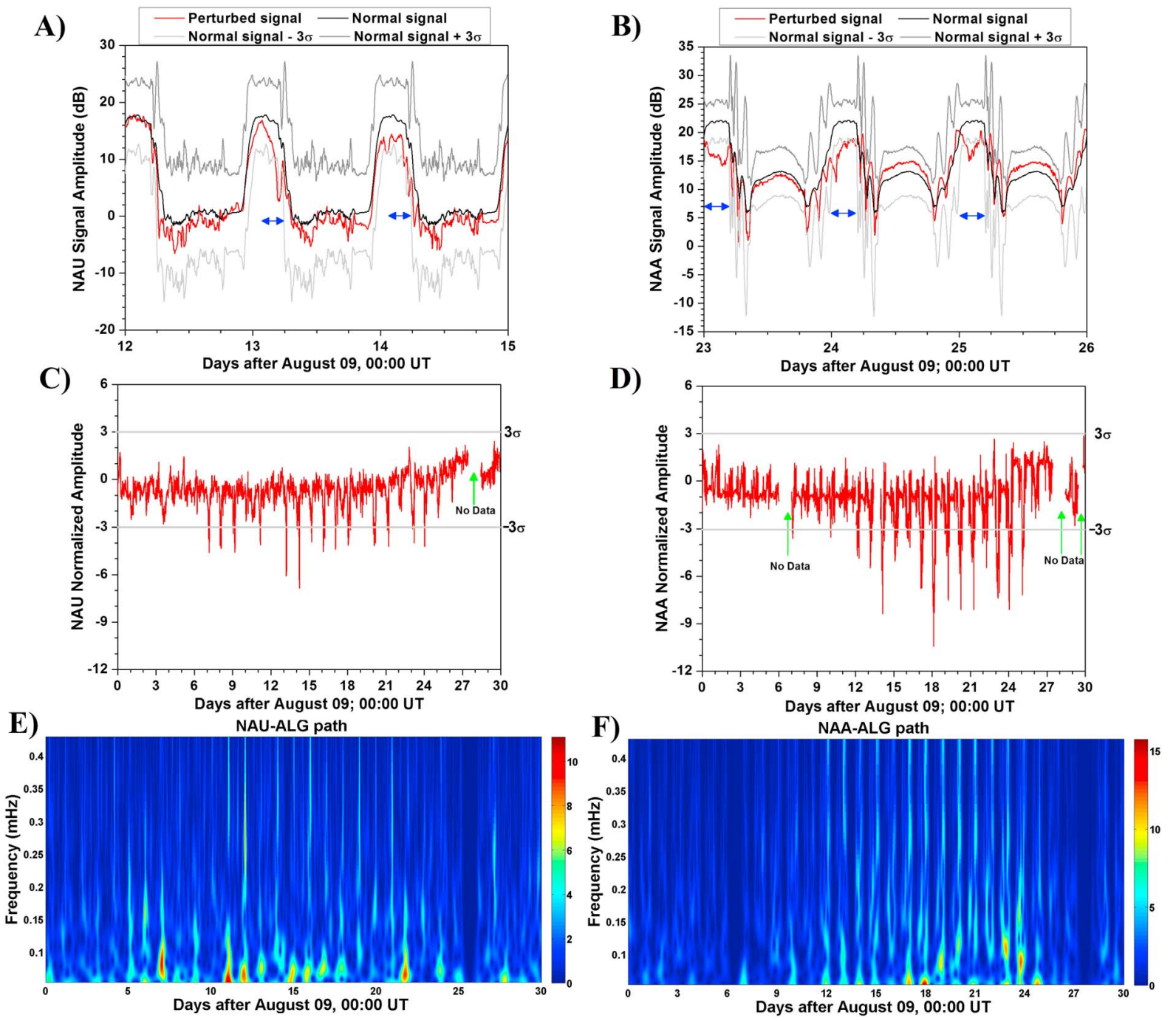

Figure 2. (a) Example of anomalies in NAU signal amplitude due to TS Fiona. (b) NAA signal amplitude anomalies due to Gaston. (c) Normalized signal amplitude of NAU and (d) NAA. Mother wavelet transform of normalized NAU signal amplitude (e) and NAA signal amplitude (f).

(day 14) when storm Karl crossed NAU-Algiers path and the storm Lisa was at 1,000 km away from NAU-Algiers path, see Figure 1d. Here again we observed a strong perturbation (decrease) at the nighttime NAU signal amplitude of $-10 \mathrm{~dB}$ on 22 and 24 September during which Karl center intercepted the GCP and was about $500 \mathrm{~km}$ away from GCP, respectively. The distances are between the storm centers and NAU-Algiers GCP. On NAA signal, a perturbation of $-9 \mathrm{~dB}$ was observed on 24 September when storm Karl was at 1,383 km and Lisa was at 2,510 km from GCP and both moved toward the path as shown in the Figure $1 \mathrm{~d}$. From the normalized amplitude plots shown in Figures $3 \mathrm{c}$ and $3 \mathrm{~d}$ we can see that the strength of the perturbations in the case of NAU signal was sometimes above and below $3 \sigma$ unlike the case of Fiona and Gaston where only decrease in the signal amplitude was observed. In the case of NAA-Algiers path the strength of the perturbations was below $3 \sigma$ and was important when Karl and Lisa approached the GCP to Algiers. The positive or negative signal amplitude perturbations are related to the modal interference of the propagating signal modes directly and those scattered from storm associated disturbed $D$-region arriving at the receiver. This modal interference can be constructive or destructive at the receiver as described by NaitAmor et al. (2016). Similarly to case 1 of the storms, the mother wavelet analysis of normalized signal amplitude shows the wave-like events with periods between 2 and $3 \mathrm{hr}$, see Figures $3 e$ and $3 \mathrm{f}$.

\subsection{Matthew and Nicole Cases}

The next interesting storms are Matthew (category- 5 hurricane), developed between 28 September and 9 October, and Nicole (category-4 hurricane), developed between 4 and 18 October. The geomagnetic Kp index 

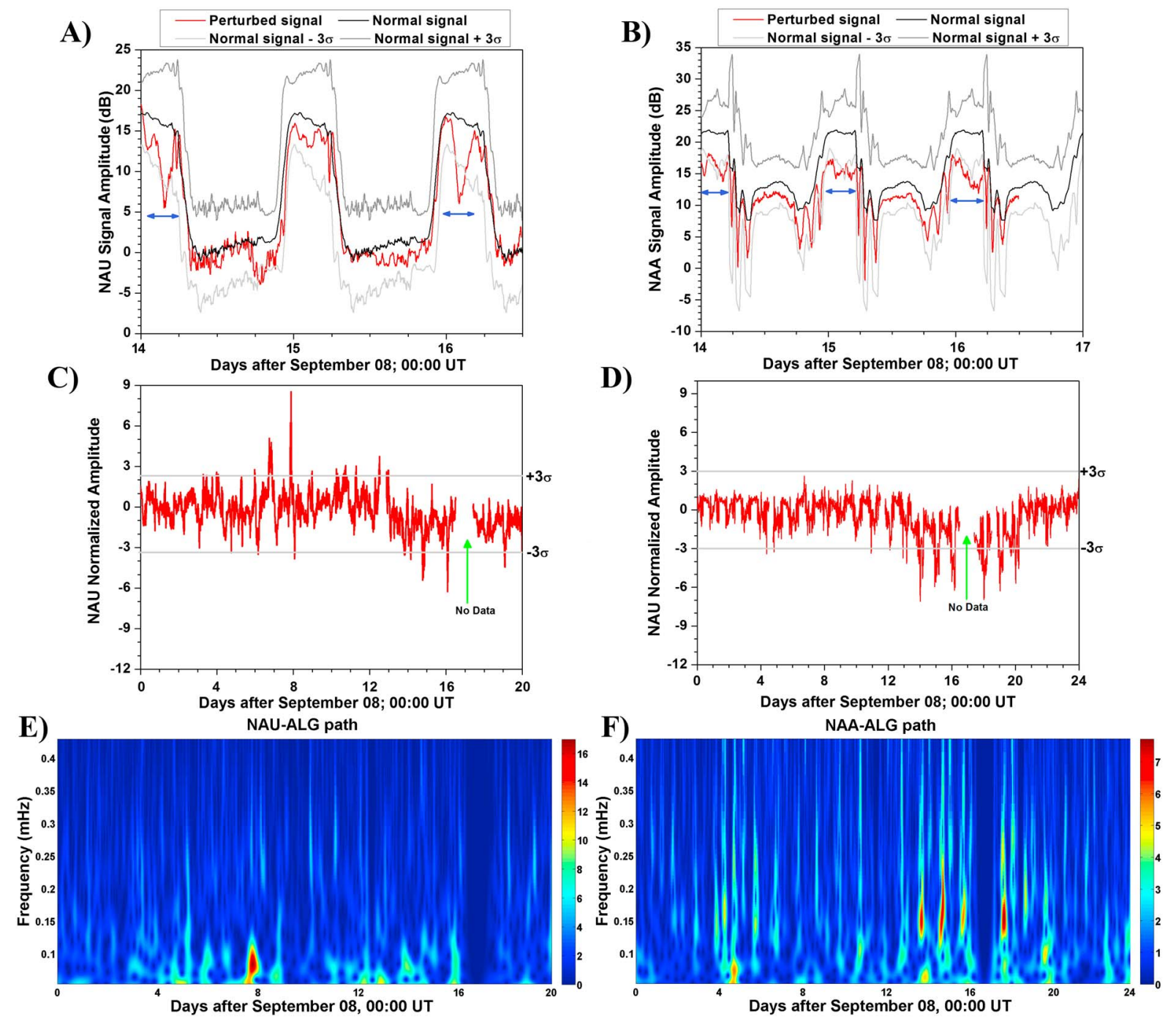

Figure 3. (top) Example of perturbations due to TS Karl in both NAU signal amplitude (a) and NAA signal amplitude (b). (middle) Normalized signal amplitude of NAU (c) and NAA (d). (bottom) Mother wavelet transform of normalized NAU signal amplitude (e) and NAA signal amplitude (f).

from 28 September to 23 October was also at low level except few days where it increased to 6 . The increase of the geomagnetic activity was due to an intense storm with minimum Dst index of $-100 \mathrm{nT}$ on 14 October. In Figure $4 \mathrm{~b}$ we show examples of two days of NAA signal amplitude variation starting from 10 October (day 11) for hurricane Matthew. For NAU transmitter, we present in Figure $4 a 3$ days of the signal amplitude starting from October 4 (day 6) during which hurricane Nicole was closer to the GCP as TD classification and hurricane Matthew's center was at $700 \mathrm{~km}$ from transmitter site, see Figure 1b. From the NAU signal amplitude plot, a clear decrease in the nighttime signal amplitude of $-8 \mathrm{~dB}$ was recorded on 4 October. On 6 October, a strong perturbation (decrease) of $-12 \mathrm{~dB}$ in the nighttime signal amplitude was recorded when Matthew was at $1,000 \mathrm{~km}$ away from NAU site and classified as hurricane category 5 , and Nicole was at $500 \mathrm{~km}$ away from GCP. In the case of NAA transmitter, an increase in the signal perturbation amplitude of $7 \mathrm{~dB}$ was recorded on 10 October during nighttime when Matthew was at its shortest distance from NAA site $(1,000 \mathrm{~km})$ and Nicole was at 2,000 km away from GCP before it was intensified to hurricane category 1 on 11 October. Additionally, the recorded amplitude of both signals showed clear nighttime wave-like events with periods between 2 and $3 \mathrm{hr}$ consistent with the period of GWs as estimated from the wavelet analysis. The normalized amplitude of both signals are presented in the Figures $4 \mathrm{c}$ and $4 \mathrm{~d}$. Here again both hurricanes were sources of strong signal perturbations when the storms were at short distances from the transmitter sites or signal GCPs. It is also observed that the perturbations persisted even if the storm was between 1,000 and 2,000 km away from 


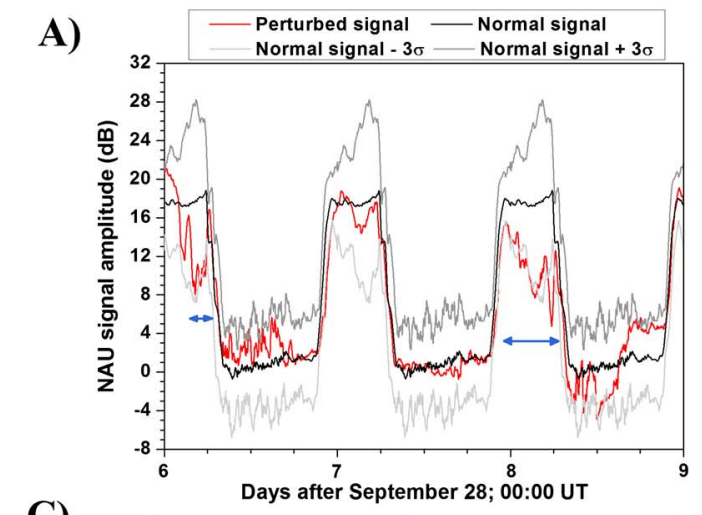

C)
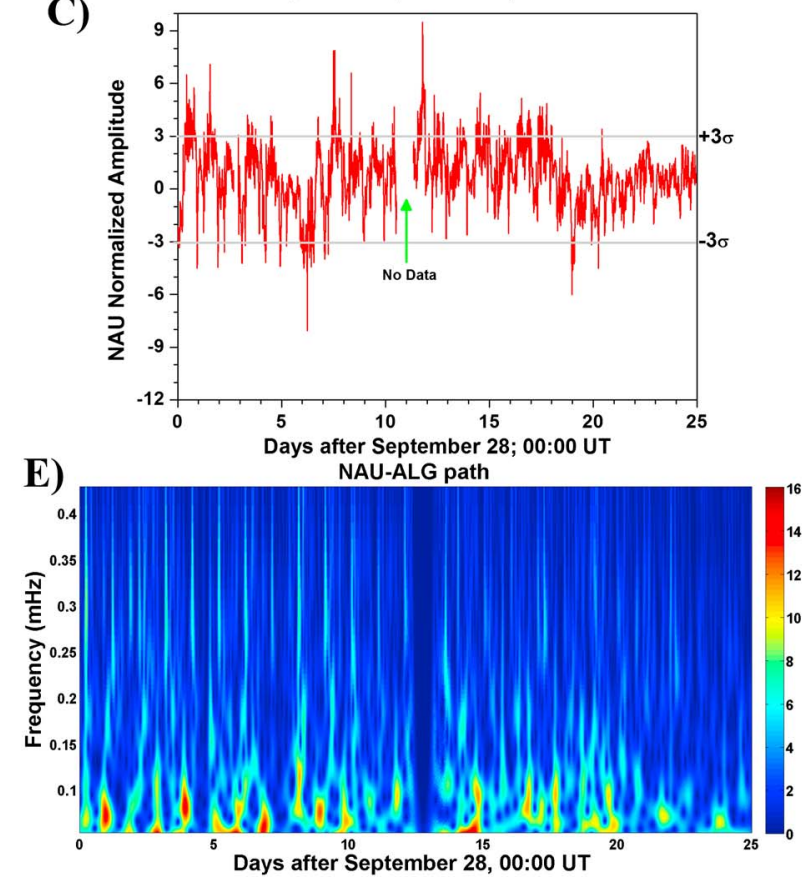

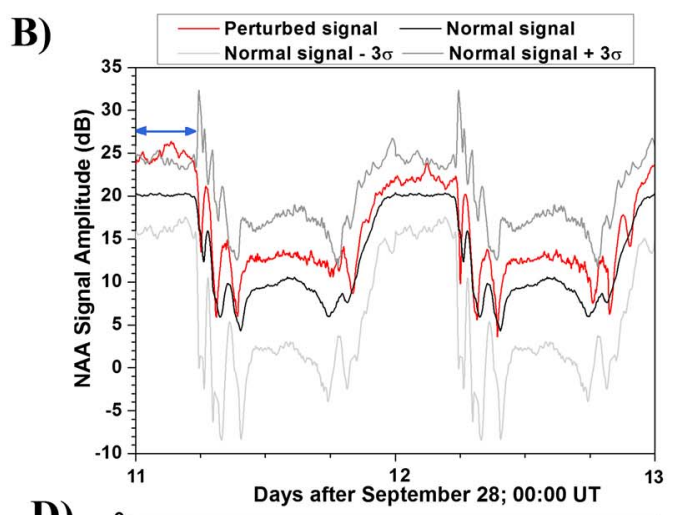

D)
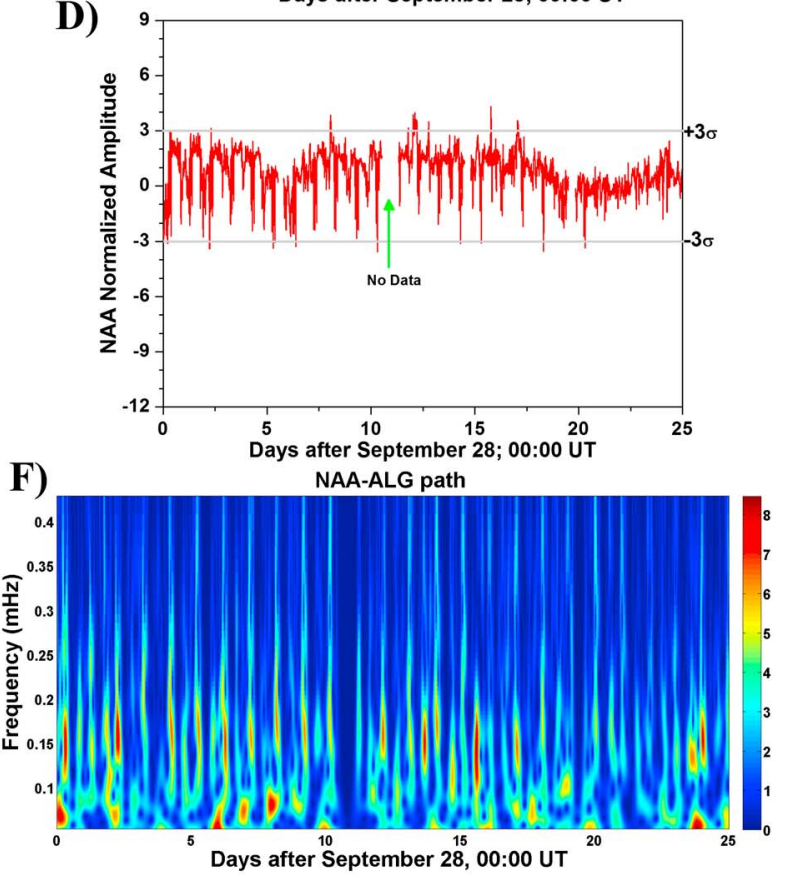

Figure 4. (top) Example of signal perturbations in NAU due to Matthew (a) and NAA due to Nicole (b). (middle) Normalized signal amplitude of NAU (c) and NAA (d). (bottom) Mother wavelet transform of normalized NAU signal amplitude (e) and NAA signal amplitude (f).

GCPs. Figures $4 \mathrm{e}$ and $4 \mathrm{f}$ are presented the mother wavelet analysis of normalized signals amplitude that shows clearly the wave-like events with periods between 2 and $3 \mathrm{hr}$.

\section{Discussion and Conclusions}

From the signals anomalies analysis related to the TSs and hurricanes, we showed that perturbations in the signal amplitude can be observed during low or high classification of the storms. Effectively, in the case of TS Fiona, we observed a signal perturbation in the NAU-Algiers path when Fiona was even classified as TD. This is in agreement with the study of Nina et al. (2017) on the observations of VLF signal anomalies during TD stages of 36 storms out of 41 in the Atlantic Ocean. It is possible for the other cases that the storm at TD classification may have perturbed the signal amplitude but since multiple storms were observed during the same period it is difficult to decide on the perturbation associated source and its classification. We also observed that the perturbations were significant when the storm approached the transmitter site or the signal path to the receiver and that the sensitivity zone can reach up to 2,000 $\mathrm{km}$ when multiple storms happen during the same period. This result is in agreement with a study by Nina et al. (2017) where anomalies in the VLF signal whose propagation path was above latitude of $40^{\circ}$ were observed in the periods around the tropical depressions whose locations were around $10^{\circ}$. As in Nina et al. (2017) and contrarily to Rozhnoi et al. (2014) who observed only negative nighttime anomalies in the signal amplitude, whereas in our case the perturbation amplitudes were both positive and negative independently to the storm category. Thus, the sign of the perturbation and 
its magnitude are mainly affected by the propagating distance of the received signal (NaitAmor et al., 2016) and the storm distance to GCP, which contribute to the constructive or destructive modal interference at the receiver resulting in a positive or a negative signal anomaly. This can be seen by comparing the hurricane Gaston case and hurricane Nicole case. The hurricane Gaston ended at short distance to the receiver location than Nicole which intercepted NAA-Algiers path at a region closer to the transmitter site than the receiver. This has a primordial effect on the modal composition of the propagating signal at the disturbance region and the receiver location. Additionally, the results revealed for the first time a clear nighttime perturbations with periods between 2 to $3 \mathrm{hr}$ in both signal paths with different shapes and magnitudes even if the associated signal perturbation amplitudes were within $\mp 3 \sigma$. These wave-like observations were also found to be independent to the convective system category. The reason why these wave-like observations were observed at nighttime only is related to the balance between the electron production and loss rates. Effectively, at nighttime the production of electrons at low altitudes is ensured by cosmic rays and that during daytime, the production is ensured by sunlight. Since the sunlight flux is much more important than cosmic rays flux, the nighttime ionosphere is then easily disturbed than the daytime ionosphere. To explore the wave-like periods recorded in association with the studied cases, we applied Morlet wavelet analysis to the normalized signal amplitude $\left(A_{\text {normalized }}\right)$ to both transmitter signals as shown in panels $(e)$ and $(f)$ of Figures 2,3 , and 4 . From the plots the main periods are between 2 and $3 \mathrm{hr}$ and are important when the storms approached the paths. Rozhnoi et al. (2014) from VLF data analysis for a TC in August 2010 estimated wave-like signature of 7-16 and 15-55 minutes and attributed these wave-like signatures to internal GWs generated by typhoon. Ming et al. (2014) using radiosonde and GPS radio occultation analysis found GWs with periods between 4.6-13 hr in the upper troposphere and lower stratosphere close to the source (TC). Kumar et al. (2017) by mother wavelet analysis of four VLF transmitters (NPM, NLK, NAA, and J) signals observed in Fiji during TC Evan 9-16 December 2012 determined wave-like events with periods between $45.7 \mathrm{~min}$ and $5.5 \mathrm{hr}$. Our results along with the previous studies (Ming et al., 2014; Rozhnoi et al., 2014; Kumar et al., 2017) indicate that wave-like signatures of wider period could be associated with TSs and hurricanes/TCs. We also found that the number of days when these waves were observed are more frequent for Matthew and Nicole than for the other storms. The reason is that these storms were most powerful, which produced strong convection/turbulence in the lower atmosphere (Ming et al., 2014).

Acknowledgments

The authors are thankful to NHC (www.nhc.noaa.gov) and CDAWeb (https://cdaweb.sci.gsfc.nasa.gov/index.html/) for keeping available online data for Dst and Kp geomagnetic indices. The VLF data are available at $\mathrm{ftp}: / / \mathrm{ftp} . c r a a g . d z / \mathrm{tmp} /$ VLFData.

\section{References}

Brissaud, Q., Martin, R., Garcia, R. F., \& Komatitsch, D. (2016). Finite-difference numerical modelling of gravitoacoustic wave propagation in a windy and attenuating atmosphere. Geophysical Journal International, 206(1), 308-327. https://doi.org/10.1093/gji/ggw121

Cohen, M. B., Gross, N. C., Higginson-Rollins, M. A., Marshall, R. A., Golkowski, M., Liles, W., et al. (2018). The lower ionospheric VLF/LF response to the 2017 great American solar eclipse observed across the continent. Geophysical Research Letters, 45, 3348-3355. https://doi.org/10.1002/2018GL077351

Cohen, M. B., Inan, U. S., \& Paschal, E. W. (2010). Sensitive broadband ELF/VLF radio reception with the AWESOME instrument. IEEE Transactions on Geoscience and Remote Sensing, 48(1), 3-17. https://doi.org/10.1109/TGRS.2009.2028334

Cohen, M. B., Said, R. K., Paschal, E. W., McCormick, J. C., Gross, N. C., Thompson, L., et al. (2018). Broadband longwave remote sensing instrumentation. Reviews of Scientific Instruments, 89, 094501. https://doi.org/10.1063/1.5041419

Ferguson, J. A. (1992). A review of the ionospheric model for the long-wave production capability (TD 2393 (Nov)). San Diego, CA: Naval Command, Control and Ocean Surveillance Center RDT and E Division.

Ferguson, J. A., \& Snyder, F. P. (1989a). Long-wave propagation capability program description and user's guide (TD 1449 (Jan)). San Diego, CA: Naval Ocean System Center. Available from Defense Technical Information Center (DTIC): ABD130808.

Garcia, R. R., \& Solomon, S. (1985). The effect of breaking gravity waves on the dynamics and chemical composition of the mesosphere and lower thermosphere (1985). Journal of Geophysical Research, 90(D2), 3850-3868. https://doi.org/10.1029/JD090iD02p03850

Haldoupis, C., Amvrosiadi, N., Cotts, B. R. T., Van der Velde, O. A., Chanrion, O., \& Neubert, T. (2010). More evidence for a one-to-one correlation between sprites and early VLF perturbations. Journal of Geophysical Research, 115, A07304. https://doi.org/10.1029/2009JA015165

Kumar, S., Kumar, A., Menk, F., Maurya, K., Singh, R., \& Veenadhari, B. (2015). Response of the low-latitude D region ionosphere to extreme space weather of 14-16 December 2006. Journal of Geophysical Research: Space Physics, 120, 788-799. https://doi.org/10.1002/2014JA020751

Kumar, S., NaitAmor, S., Chanrion, O., \& Neubert, T. (2017). Perturbations to the lower ionosphere by tropical cyclone Evan in the South Pacific Region. Journal of Geophysical Research: Space Physics, 122, 8720-732. https://doi.org/10.1002/2017JA024023

Liu, H.-L., McInerney, J. M., Santos, S., Lauritzen, P. H., Taylor, M. A., \& Pedatella, N. M. (2014). Gravity waves simulated by high-resolution whole atmosphere community climate model. Geophysical Research Letters, 41, 9106-9112. https://doi.org/10.1002/2014GL062468

Marshall, R. A., \& Snively, J. B. (2014). Very low frequency subionospheric remote sensing of thunderstorm-driven acoustic waves in the lower ionosphere. Journal of Geophysical Research: Atmospheres, 119, 5037-5045. https://doi.org/10.1002/2014JD021594

Ming, F. C., Ibrahim, C., Barthe, C., Jolivet, S., Keckhut, P., Liou, Y.-A., \& Kuleshov, Y. (2014). Observation and a numerical study of gravity waves during tropical cyclone Ivan (2008). Atmospheric Chemistry and Physics, 14, 641-658. https://doi.org/10.5194/acp-14-641-2014

NaitAmor, S., AlAbdoadaim, M. A., Cohen, M. B., Cotts, B. R. T., Soula, S., Chanrion, O., et al. (2010). VLF observations of ionospheric disturbances in association with TLEs from the EuroSprite-2007 campaign. Journal of Geophysical Research, 115, A00E47. https://doi.org/10.1029/2009JA015026 
NaitAmor, S., Cohen, M. B., Cotts, B. R. T., AlAbdoadaim, H., Ghalila, M. A., \& Graf, K. (2013). Characteristics of long recovery early VLF events observed by the North African AWESOME Network. Journal of Geophysical Research: Space Physics, 118, 5215-5222. https://doi.org/10.1002/jgra.50448

NaitAmor, S., Ghalila, H., \& Cohen, M. B. (2016). TLEs and early VLF events: Simulating the important impact of transmitter-disturbance-receiver geometry. Journal of Geophysical Research: Space Physics, 121, 1. https://doi.org/10.1002/2016JA022791

Nina, A., \& Cadez, V. M. (2013). Detection of acoustic-gravity waves in lower ionosphere by VLF radio waves. Geophysical Research Letters, 40 4803-4807. https://doi.org/10.1002/grl.50931

Nina, A., Radovanovic, M. M., Milovanovic, B. M., Kovacevic, A. B., Bajcetic, J. B., \& Popovic, L. C. (2017). Low ionospheric reactions on tropical depressions prior hurricanes. Advances in Space Research, 60(8), 1866-1877. https://doi.org/10.1016/j.asr.2017.05.024

Raulin, J.-P., Trottet, G., Kretzschmar, M., Macotela, E. L., Pacini, A., Bertoni, F. C. P., \& Dammasch, I. E. (2013). Response of the low ionosphere to X-ray and Lyman- $\alpha$ solar flare emission. Journal of Geophysical Research: Space Physics, 118, 570-575. https://doi.org/1029/ 2012JA17916

Rozhnoi, A., Solovieva, M., Levin, B., Hayakawa, M., \& Fedun, V. (2014). Meteorological effects in the lower ionosphere as based on VLF/LF signal observations. Natural Hazards and Earth System Sciences, 14, 2671-2679. https://doi.org/10.5194/nhessd-2-2789-2014

Salut, M. M., Abdullah, M., Graf, K. L., Cohen, M. B., Cotts, B. R. T., \& Kumar, S. (2012). Long recovery VLF perturbations associated with lightning discharges. Journal of Geophysical Research, 117, A08311. https://doi.org/10.1029/2012JA017567

Sato, K., Watanabe, S., Kawatani, Y., Tomikawa, Y., Miyazaki, K., \& Takahashi, M. (2009). On the origins of mesospheric gravity waves. Geophysical Research Letters, 36, L19801. https://doi.org/10.1029/2009GL039908

Thomson, N. R., Rodger, C. J., \& Clilverd, M. A. (2005). Large solar flares and their ionospheric D-region enhancements. Journal of Geophysical Research, 110, A06306. https://doi.org/10.1029/2005JA011008 